\title{
GÊNERO E SEXUALIDADE: REFLEXÕES ACERCA DO IMAGINÁRIO SOCIAL DOCENTE NA EDUCAÇÃO DE SURDOS
}

\author{
Márcia Beatriz Cerutti Müller ${ }^{1}$ \\ Denise Regina Quaresma da Silva ${ }^{2}$ \\ Maria Angela Mattar Yunes ${ }^{3}$
}

\section{INTRODUÇÃO}

Este artigo tem como objetivo provocar reflexões sobre a surdez, na perspectiva de gênero e sexualidade, pensada na formação docente. Pretende-se analisar esta formação a partir das diferenças culturais e da constituição do imaginário social das/os docentes. Trata-se de um estudo de cunho bibliográfico exploratório, resultante de discussões realizadas numa disciplina intitulada Gênero, subjetividade e formação docente ocorridas num Programa de Pós Graduação em Educação do Rio Grande do Sul que utilizou como fontes teóricas livros e artigos publicados.

O referencial teórico fundamenta-se nos pressupostos de autoras/es que discutem as temáticas referidas. São eles: Castoriadis (1982), Louro (2008, 2010), Quaresma da Silva (2012) e Skliar (1997, 1999, 2003). São autoras/es que contribuem com a discussão sobre a educação nos diferentes discursos, sobre o imaginário social, os mitos $\mathrm{e}$ as diferentes formas de narrar os sujeitos, problematizando as questões que envolvem a surdez, gênero e sexualidade e a formação docente.

\footnotetext{
${ }^{1}$ Pedagoga: Psicopedagoga; Mestre em Educação e Doutoranda em Educação no Programa de Pósgraduação em Educação do UNILASALLE.

${ }^{2}$ Pós Doutora em Estudos de Gênero, Doutora em Educação, Psicóloga, Professora do Programa de Pós Graduação em Educação do Centro Universitário La Salle - UNILASALLE e do PPG em Diversidade Cultural e Inclusão Social da Universidade Feevale.

${ }^{3}$ Psicóloga; Mestre em Psicologia do Desenvolvimento pela University of Dundee, Escócia; Doutora em Educação: Psicologia da Educação pela PUC/SP; Professora permanente no Programa de Pósgraduação em Educação do UNILASALLE; Professora colaboradora no Programa de Pós-graduação em Educação Ambiental na FURG, Rio Grande, RS.
} 


\section{ASPECTOS HISTÓRICOS: SURDEZ, GÊNERO E SEXUALIDADE}

Conhecer, mesmo que de forma breve, a história dos sujeitos surdos ${ }^{4}$ permite-nos entender as representações e pressupostos políticos e filosóficos existentes. Acreditamos que as formas de narrar a surdez e os sujeitos surdos são produzidas a partir dos significados dados em cada momento da sua história.

Encontramos, na antiguidade, o sacrifício de pessoas surdas em função de um padrão de normalidade e perfeição. Havia a crença de que tais pessoas não tinham capacidade cognitiva para adquirir uma linguagem e aprender. Foi um longo percurso, desde a eliminação até a possibilidade de serem educadas, ou instruídas. De acordo com Guarinello, (2007, p.20) "A primeira alusão à possibilidade de instruir os surdos por meio da língua de sinais e da linguagem oral foi feita por Bartolo della Marca d'Ancona, escritor do século XIV". Esse foi o início de reconhecimento de que estas pessoas poderiam tomar suas próprias decisões.

Pedro Ponce de León (séc. XVI), monge beneditino foi considerado o primeiro professor de surdos e ensinava crianças surdas, filhas de nobres, "[...] a fim de ser reconhecidos como pessoas nos termos da lei e herdar os títulos e as propriedades da família, já que os mudos não tinham este direito". (GUARINELLO, 2007, p.21). Posteriormente Juan Pablo Bonet desenvolveu tais atividades reconhecendo a necessidade de ensinar os surdos individualmente, já evidenciada por seu antecessor, para evitar distrações. O ensino coletivo para alunos surdos, iniciou em Paris, quando por volta do ano de 1760 Charles Michel de L'Épée fundou a primeira escola pública.

No Brasil, o ensino de pessoas surdas iniciou em 1857 sob a influência do Instituto de Paris. A convite de Dom Pedro II, Ernest Huet, iniciou suas atividades como professor, nascendo assim, a primeira escola para surdos-mudos no Rio de Janeiro, hoje Instituto Nacional de Educação de Surdos (INES).

\section{DISCURSOS SOCIAIS E ESTEREÓTIPOS}

\footnotetext{
${ }^{4}$ Usamos o termo surdo para referir a pessoas que não utilizam a audição de maneira funcional, independente da perda auditiva. Entendemos a surdez como diferença linguística e cultural.
} 
Olhando para a história, percebe-se as diferentes formas de representação sobre a surdez e os surdos. De acordo com Skliar (1997, p.115): "Os livros da psicologia da surdez definem os surdos como linguisticamente pobres, intelectualmente primitivos e concretos, socialmente isolados e psicologicamente imaturos e agressivos". Ou seja, todos são olhados de forma coletiva, o que torna as discussões acerca dos discursos sociais sobre este grupo, fundamentais.

Até recentemente, os profissionais é que narravam, pensavam, construíam e julgavam os sujeitos da educação especial. Segundo este autor, tal prática "[...] serviu ao propósito institucional de fronteira de inclusão/exclusão, porém fracassou na compreensão e justificação de sua própria história, seus saberes, mediações e mecanismos de poder" (p. 19). O autor afirma ainda, que o discurso da deficiência tende a mascarar a questão política da diferença, que [...] passa a ser definida como diversidade que é entendida quase sempre como a/s variante/s aceitáveis e respeitáveis do projeto hegemônico da normalidade”. (SKLIAR, 1999, p. 21)

Atualmente, a surdez configura-se "[...] como um território de representações que não podem ser facilmente delimitadas ou distribuídas em modelos conceituais opostos", o modelo clínico centralizado na noção de deficiência $X$ modelo socioantropológico, baseado na noção de diferença. "Trata-se, melhor dizendo, de um território irregular por onde transitam discursos e práticas assimétricos quanto às relações de poder/saber que determinam". Segundo o autor, "Passar de naturalização da medicina à curiosidade da etnografia ao reconhecimento político da diferença, não é simplesmente, trocar uma roupa antiga por uma nova" (SKLIAR, 2003, p. 93). Para Skliar as representações não estão necessariamente separadas nas práticas discursivas e nos dispositivos pedagógicos.

Este olhar para a história, oportuniza conhecer diferentes formas de narrar e educar pessoas surdas. Podemos incluir aqui também as diferentes maneiras de entender e representar tais sujeitos no que se refere a gênero e sexualidade. Lebedeff (2010), afirma: "Falar de sexualidade não é tarefa fácil, principalmente por se tratar de um assunto impregnado tanto por simbologias (muitas vezes inconscientes), quanto por valores culturais (conscientes ou não) ". Segundo a autora, geralmente a sexualidade é trabalhada apenas como uma questão biológica e a literatura apresenta a visão ambígua sobre a sexualidade das 
pessoas com deficiência. Para muitos, a pessoa com deficiência é assexuada, comparada a uma criança e outros as percebem como hipersexuada, mas sem afetividade.

A história relata que desde o início da educação de surdos no Brasil, alunas surdas foram discriminadas quando o Instituto Nacional dos Surdos-Mudos, fundado em 1856, deixou de recebe-las em 1868, devido a possível promiscuidade. Somente em 1932, as meninas retornaram à escola. Havia o entendimento de que meninas não educadas não seriam problema, meninos sim. Segundo Klein e Formozo (2007), as surdas são discriminadas no mercado de trabalho em geral, contudo, "[...] são a maioria no professorado, o que é uma consequência da feminização do trabalho docente". A crença na vocação contribui para justificar tal escolha.

Os educadores e educadoras aceitaram e expressaram o conceito de vocação, segundo Bruschini e Amado (1998, p.7, apud SANTOS, 2008, p.3), "[...] a escolha da carreira devia ser adequada à natureza feminina, atividades requerendo sentimento, dedicação, minúcia e paciência deveriam ser preferidas". Sob o argumento de que as pessoas tinham "[...] aptidões e tendências inatas" para determinadas áreas, "[...] o conceito de vocação foi um dos mecanismos mais eficientes para induzir as mulheres a escolher as profissões menos valorizadas socialmente". Ressaltamos que as relações de gênero são produzidas e estabelecidas de acordo com as concepções vigentes na sociedade que esta constrói os papeis e representações acerca do que é de e ser mulher e o que é de e ser homem. No entender de Scott (1995),

\footnotetext{
Cuando planteo la existencia de creencias sobre género y sexualidad me coloco en una comprensión cultural de las diferencias entre hombres y mujeres, interpretando el género como "un elemento constitutivo de relaciones sociales basadas en las diferencias percibidas entre los sexos y como una forma primaria de dar significado a las relaciones de poder". (SCOTT, 1995, p. 86).
}

Butler (2010), afirma que as feminidades e as masculidades são ensinadas, produzidas, construídas. Quaresma da Silva (2012) reitera que são "[...] inventadas y ordenadas como resultado de desiguales relaciones de poder que tienen lugar en una determinada sociedad, y están marcadas por las particularidades del contexto histórico cultural donde ellas emergen”. Enfatizamos que feminidades e 
masculinidades formam um conjunto de significados e comportamentos atravessados por marcas de identidade.

Desta forma, refletir sobre a formação docente, conhecer suas crenças/representações em relação a surdez e aos sujeitos surdos, gênero e sexualidade torna-se relevante visto que, podem constituir-se como verdades que impactam na educação e nas práticas educativas. Vivemos numa sociedade plural e buscamos uma sociedade onde as relações viabilizem a valorização, o reconhecimento das diferenças, o acolhimento de todos os sujeitos e a cultura da paz. Uma diversidade de textos legais postula estas questões no Brasil.

Destacamos entre os textos, documentos tais quais: a Declaração Universal dos Direitos Humanos (1948), Constituição Federal (1988), A Declaração Mundial sobre Educação para Todos (1990), a Declaração de Salamanca (1994), a Lei de Diretrizes de Base da Educação Nacional (Lei Federal no 9394/96), o Estatuto da Criança e do Adolescente - ECA (Lei no 8069 de 13 de julho de 1990), os Parâmetros Curriculares Nacionais - PCNs, (1997) e o Plano Nacional de Educação - PNE (Lei no 13.005, de 25 junho de 2014).

Entretanto, acreditamos que não basta existirem textos legais e reguladores. É preciso haver conhecimento e conscientização das pessoas. Faz-se necessária a ruptura com estereótipos existentes que apenas levam a uma "comodidade cognitiva" sem reflexão crítica sobre o tema. Percebe-se que facilmente criam-se estereótipos em relação a surdez, e estes "estereótipos dão origem ao estigma que vem sinalizar suspeita de ódio e intolerância dirigidos a determinado grupo, inviabilizando sua inclusão social". (QUARESMA DA SILVA e MELLO, 2008).

Diante de situações cotidianamente vivenciadas nas escolas, questionamos quais discursos vêm influenciando o imaginário social das/os docentes e quais as implicações destes discursos nas práticas pedagógicas? Como as/os docentes vivenciam sua práxis $^{5}$ e como veem os sujeitos surdos, especialmente em relação a gênero e sexualidade?

\footnotetext{
"Chamamos de práxis este fazer no qual o outro ou os outros são visados como seres autônomos e considerados como o agente essencial do desenvolvimento de sua própria autonomia". (CASTORIADIS, 1982, p. 94)
} 
Percebemos, na história dos surdos, muitos discursos foram construídos e não raro, ainda hoje se ouve: "os surdos são assim", "surdo pode", "surdo não pode". Os discursos e o desconhecimento da área, faz com que estereótipos sejam criados e mantidos. Assim, é importante ressaltar que a surdez não pressupõe uma identidade única. Desta forma, entendemos que problematizar os conhecimentos acerca da surdez, especialmente em relação a gênero e sexualidade é pertinente num estudo e esse foi o nosso desafio. Quaresma da Silva (2012) afirma que "las creencias y valores associados a los modos de ser hombres y mujeres permean las prácticas de educación sexual y determinan la forma em la que son descritas diversas identidades". Assim como as marcas que são dadas às pessoas consideradas fora de uma norma social preexistente pode deixá-las às margens de uma cultura dominante.

Para Louro (2013, p.44), “'Novas' identidades culturais obrigam a reconhecer que a cultura, longe de ser homogênea e monolítica, é, de fato, complexa, múltipla, desarmoniosa, descontínua". A autora fala da necessidade de sair do centro, de reconhecer as diferenças existentes. Contudo, afastar-se de um padrão, significa buscar o desvio e tornar-se excêntrico. Já, ficar no centro significa ficar em lugar confortável. Postula também que as produções da cultura construídas fora do centro assumem um caráter de "diferenças", algumas vezes excluídas dos currículos, em outras, ocupando um lugar de exótico. Entretanto, tal situação mantém um lugar especial para as identidades "marcadas". Modificar essa situação seria possível se fossem consideradas as formas como as diferenças são produzidas e nomeadas a partir do interior de uma cultura e demarcando fronteiras (grifos do autor).

Importante refletir sobre uma "mudança epistemológica", nos discursos e nas representações que atribuem o significado de diferente aos corpos e às identidades, traduzindo em hierarquias que são atribuídas aos sujeitos e muitas vezes, assumidas por eles. Louro (2013) ressalta que educadoras/es precisam "[...] saber como se produzem os discursos que instituem diferenças, quais os efeitos [...], quem é marcado como diferente, como currículos e outras instâncias pedagógicas representam os sujeitos [...]", além disso, "[...] que possibilidades, destinos e restrições a sociedade Ihes atribui" (LOURO, 2013, p. 49). Nesse sentido, a diferença se constitui numa relação e não pode ser eliminada, ela é uma produção social e relacional, é múltipla, está em ação e é provisória. Diante do exposto, refletir 
sobre a formação docente e sobre o imaginário social que pode estar permeado por 'verdades' nos espaços escolares e também nos diferentes espaços da sociedade, é urgente.

\section{O IMAGINÁRIO SOCIAL E A DOCÊNCIA}

Ao refletirmos sobre relações de aprendizagem, precisamos lembrar dos medos, dos preconceitos, dos mitos que as pessoas têm acerca das diferenças. Os mitos, no entender de Eliade (1994, p. 11) são "[...] uma realidade cultural extremamente complexa, que pode ser abordada e interpretada através de perspectivas múltiplas e complementares". Os mitos carregam algo oculto, e ocupam um lugar num momento em que não há uma definição, se não questionados tornamse verdades nos espaços onde circulam.

Sabemos que a evolução de seres humanos se dá em função das relações estabelecidas e também a partir da maneira como se organizam. Portanto, fazer uma reflexão sobre essas relações e sobre os sujeitos envolvidos é pertinente pois os mitos são gerados também nas interações. O sujeito traz consigo sua cultura porque é constituído dentro de um contexto sociocultural. Desta forma, o sujeito sócio histórico, é constituído e constituinte de relações sociais.

Os estudos sobre o imaginário social apoiados em Castoriadis referemse a um sistema de significações que toda e qualquer sociedade possui, ou seja, refere-se à dimensão simbólica, pois o Imaginário utiliza-se do simbólico para se manifestar, traduzindo as crenças e os mitos que as pessoas e as sociedades têm. Este autor afirma ainda: "[...] Tudo o que se nos apresenta, no mundo socialhistórico, está indissociavelmente entrelaçado com o simbólico. Não que se esgote nele". (CASTORIADIS, 1982, p. 142).

Nessa perspectiva, compreender o imaginário social das/os docentes permitirá conhecermos quais os seus entendimentos acerca da surdez e dos sujeitos surdos, de gênero e sexualidade e a partir daí pensar numa formação, quem sabe, mais efetiva. Gatti (2003, p.196 apud SCOZ, 2012, p.47), contribui nesta reflexão ao afirmar que "É preciso ver os professores não como seres abstratos, ou essencialmente intelectuais, mas como seres essencialmente sociais, com suas identidades pessoais e profissionais, [...]", além disso, pertencem a um grupo onde 
partilham uma cultura, de onde vêm seus conhecimentos, seus valores e suas atitudes.

\section{METODOLOGIA}

Trata-se de um estudo de cunho bibliográfico exploratório articulado a partir dos Estudos Surdos, Estudos Culturais e Estudos de Gênero. O referencial teórico fundamenta-se nos pressupostos de autoras/es que discutem as temáticas, especialmente: Castoriadis (1982), Louro (2008, 2014), Quaresma da Silva (2012) e Skliar (1997, 1999, 2003). São autoras/es que contribuem com a discussão sobre a educação e seus diferentes discursos com foco: no imaginário social, nos mitos e nas diferentes formas de narrar os sujeitos. Questionamos quais os discursos que vêm influenciando o imaginário social das/os docentes e quais as implicações destes nas práticas pedagógicas. Buscou-se compreender ainda, a forma como as/os docentes vivenciam sua práxis e percebem os sujeitos surdos, especialmente em relação a gênero e sexualidade. Estabelecemos um diálogo com autores e pesquisas existentes no campo da surdez.

\section{RESULTADOS E DISCUSSÃO}

Entre os textos legais citados, destacamos o PNE/2014 ${ }^{6}$, que apresenta diretrizes, estabelece metas e estratégias para a educação. Elencamos, entre as diretrizes, especialmente a III e a IX que tratam respectivamente: da "superação das desigualdades educacionais, com ênfase na promoção da cidadania e na erradicação de todas as formas de discriminação" e da "valorização dos (as) profissionais da educação".

Articulamos estas duas diretrizes na tentativa de tecer reflexões acerca dos sujeitos envolvidos nas relações que existem e/ou necessariamente precisam existir em uma sociedade que se diz "ser para todos". Entendemos o docente, como um ser social inserido em um contexto histórico, com seus imaginários, suas conexões estabelecidas nas práticas pedagógicas e as possíveis rupturas que podem levar a ressignificação de seus saberes. Portanto, pensar em educação para

\footnotetext{
${ }^{6}$ Plano Nacional de Educação, aprovado pela Lei 13005/2014.
} 
todos, em igualdade de oportunidades é, antes de tudo, estar aberto para o novo, reconhecer e respeitar as diferenças, romper paradigmas, é desacomodar-se e disponibilizar-se para novas demandas.

O PNE, em sua diretriz III, trata da "superação das desigualdades educacionais, com ênfase na promoção da cidadania e na erradicação de todas as formas de discriminação"'. Segundo Louro (2008), as noções de norma e diferença tornaram-se relevantes na contemporaneidade com uma reflexão sobre os significados. De acordo com esta autora, a norma é um princípio de comparação e está em toda parte e é capaz de naturalizar. Já a diferença, pode-se dizer que é um atributo e se constitui em uma relação. A diferença não preexiste nos corpos dos indivíduos, ela é atribuída quando relacionada a outro sujeito que é tomado como referência. Frequentemente "[...] as marcas da diferença são inscritas e reinscritas pelas políticas e pelos saberes legitimados, reiteradas por variadas práticas sociais e pedagogias culturais" (LOURO, 2008). Estas inscrições adquirem significados no interior de uma cultura, podemos perceber então, que a diferença é produzida e ensinada.

Frente às situações que estão sendo apresentadas na educação brasileira, urge pensarmos na formação docente. Muitos dos discursos das/os docentes que vinham até então sendo configurados como somente falta de formação, fizeram com que pensássemos mais atentamente sobre as questões que surgiam em nossa práxis. Sendo assim, passamos a refletir para além da referida formação e, percebemos que é preciso entender, antes de tudo, as questões que estão postas no imaginário docente para, a partir daí, pensar na ressignificação dos seus saberes. Quem sabe, desta forma, possa ver este "outro que é diferente"8 e que precisa ser reconhecido e respeitado como tal.

Ao abordar a "Valorização dos (as) profissionais da educação", percebemos, a necessidade de investir na formação docente, não oferecendo somente conteúdos e informações, mas sobretudo pensando as/os docentes como um todo, com seus medos, preconceitos, mitos, crenças, afetividade enfim, é preciso pensar sujeito e subjetividade. De acordo com Scoz, (2012, p. 47), "A natureza complexa do sujeito e da subjetividade tem sido pouco considerada na educação".

\footnotetext{
${ }^{7}$ Grifo nosso.

${ }^{8}$ Grifo nosso.

${ }^{9}$ Grifo nosso
} 
Nessa perspectiva, percebe-se a importância em estudar a constituição do sujeito sócio histórico e o imaginário social, pois ao pensarmos as relações de aprendizagens, não podemos esquecer-nos de todos os medos, os preconceitos, os mitos que as pessoas têm acerca da diferença.

Diante das reflexões expostas, ressaltamos as considerações de Quaresma da Silva (2012) sobre examinar as práticas de educação sexual "con una perspectiva de gênero en las instituiciones escolares, significa desvelar lo que en ellas se enseña sobre como deben hombres e mujeres, [...]". Tais práticas em relação a abordar a sexualidade na escola, tão temidas e delegadas a outrem, ou por muitas vezes apagadas/silenciadas, independentemente dos discursos ou da intenção de ter uma disciplina que trate do assunto, pois "[...] a sexualidade está na escola porque ela faz parte dos sujeitos, ela não é algo que possa ser desligado ou algo do qual alguém possa se "despir"10. (LOURO, 2014, p.85). A formação docente deve ser adequada aos sujeitos surdos que, muitas vezes por não haver um processo comunicacional adequado ficam a margem, não recebem as informações necessárias no ambiente familiar e frequentemente não são abordadas tais temáticas na escola. O tema da sexualidade raramente é trabalhado na escola com surdos e quando o é, segue um percurso parecido com as demais escolas, abordando somente a dimensão biológica e preventiva, o que é relevante, mas não dá conta da sexualidade humana.

\section{CONSIDERAÇÕES FINAIS}

Propomos, neste estudo, refletir sobre a formação docente necessária, com um olhar mais abrangente para pensar escolas, formação e informações, uma sociedade plural na e pela cultura da paz. Deixar de negar as diferenças, possibilitar o acesso ao conhecimento, dar visibilidade e qualificar a formação docente para lidar com surdez e suas singularidades pode dar sentido às demandas subjetivas de docentes.

Ressaltamos a necessidade de, ao pensar a formação docente, priorizar a visão destes, como seres sociais, com suas identidades, imersos em grupos com uma cultura própria e que através das experiências vividas em seus percursos de

\footnotetext{
${ }^{10}$ Grifo da autora.
} 
formação vão se constituindo profissionais. Acreditamos que uma sociedade inclusiva, uma sociedade para todos, pressupõe também a formação de docentes a partir de um olhar para seus medos, mitos, crenças e desejos. Dar visibilidade aos sujeitos e qualificar a formação docente (re) visitando conceitos e discursos naturalizados em contextos históricos é um caminho a ser trilhado.

Desmistificar questões em relação à surdez, sexualidade e gênero como algo exclusivamente biológico e pensá-las a partir de construções culturais/sociais pode auxiliar as/os docentes a compreenderem o complexo sistema de valores e crenças que permeiam seus saberes na perspectiva das expressões de sexualidade. Para tanto, (re) tornamos ao início deste estudo quando ressaltamos a necessidade de romper com estereótipos pré-existentes para pensar o outro como alteridade, aquele que é diferente de si mesmo.

\section{REFERÊNCIAS}

BRASIL, LEI № 13.005, DE 25 DE JUNHO DE 2014. Aprova o Plano Nacional de Educação - PNE e dá outras providências. Disponível em: < http://www.planalto.gov.br/ccivil_03/_Ato2011-2014/2014/Lei/L13005.htm>. Acesso em: 20 jul. 2015.

BUTLER, J. Corpos que pesam: sobre os limites discursivos do "sexo". (151-172) In: LOURO, GUACIRA L. O corpo educado: pedagogias da sexualidade. Belo Horizonte: Autêntica, 2010.

CASTORIADIS, CORNELIUS. A Instituição Imaginária da Sociedade. Rio de Janeiro: Paz e Terra, 1982.

ELIADE, MIRCEA. Mito e Realidade. Trad. Pola Civelli. São Paulo: Ed. Perspectiva, 1994.

GUARINELLO, ANA CRISTINA. O papel do outro na escrita de sujeitos surdos.

São Paulo: Plexus, 2007.

KLEIN, MADALENA e FORMOZO, DANIELA de P. Gênero e Sexualidade. (2007) Disponível em: https://online.unisc.br/seer/index.php/reflex/article/viewFile/225/172. Acesso em: 28/10/2014

LEBEDEFF, TATIANA B. Surdez e sexualidade: uma discussão sobre a necessidade de empoderamento linguístico e acesso à informação. (2010). 
Disponível em:

http://www.portalanpedsul.com.br/admin/uploads/2010/Educacao_Especial/Trabalho/09_09

00_SURDEZ_E_SEXUALIDADE_UMA_DISCUSSAO_SOBRE_A_NECESSIDADE_DE_EM PODERAMENTO_LINGUISTICO_E_ACESSO_A_INFORMACAO.PDF. Acesso em: $28 / 10 / 2014$

LOURO, GUACIRA LOPES. Gênero e sexualidade: pedagogias contemporâneas. Pro-Posições, v.19, n.2 (56) - maio/ago. 2008. Disponível em:

http://www.scielo.br/pdf/pp/v19n2/a03v19n2.pdf. Acesso em: 01/12/2014

. Gênero, sexualidade e educação: uma perspectiva pós-

estruturalista. 16. ed. Petrópolis,RJ: Vozes, 2014.

LOURO, GUACIRA L. Currículo, gênero e sexualidade: o normal, o diferente o excêntrico. In.: LOURO, GUACIRA L.; FELIPE, JANE; GOELLNER, SILVANA V. (orgs.) Corpo, gênero e sexualidade: um debate contemporâneo. 9. ed, Petropolis, RJ: Vozes, 2013

QUARESMA DA SILVA, DENISE R. La producción de lo normal y lo anormal: um estúdio sobre creencias de gênero y sexualidad entre docentes se escuelas municipales de Novo Hamburgo/ Brasil. Disponível em:

http://www.scielo.org.ar/scielo.php?pid=\$185273102012000100008\&script=sci_artte $x t \& t / n g=e n$. Aceso em: 27/10/2014.

QUARESMA DA SILVA, DENISE R.; MELLO, ELIANA M. de. Discurso e gênero: uma discussão sobre modos de enunciar o feminino. Disponível em:

http://www.fazendogenero.ufsc.br/8/sts/ST54/Silva-Mello_54.pdf. Acesso em:

27/10/2014

SANTOS, ELIZABETH ÂNGELA dos. Profissão docente: uma questão de gênero? Disponível em:

http://www.fazendogenero.ufsc.br/8/sts/ST8/Elizabeth_Angela_dos_Santos_08.pdf. Acesso em: 02/12/2014

SCOTT, JOAN. Gênero: uma categoria útil de análise histórica. Educação e Realidade, Universidade Federal do Rio Grande do Sul, 20 (2), 71-99, 1995

SCOZ, BEATRIZ. Identidade e subjetividade de professores: sentidos do aprender e do ensinar. 2, ed. Petrópolis, RJ: Vozes, 2012.

SKLIAR, CARLOS (Org.) Educação e exclusão: Abordagens socioantropológicas em educação especial. Porto Alegre: Mediação, 1997. 
A invenção e a exclusão da alteridade "deficiente" a partir dos significados da normalidade. In: Educação e Realidade, Universidade Federal do Rio Grande do Sul, 24 (1), jul/dez., 15-32, 1999.

Perspectivas políticas e pedagógicas da educação bilíngue para surdos. In: SILVA SHIRLEY; VIZIM, MARLI (org.). Educação Especial: múltiplas leituras e diferentes significados. Campinas, SP: Mercado de Letras: Associação de Leitura do Brasil - ALB, 2003 (1르 reimpressão). 